\title{
PENGEMBANGAN MEDIA PEMBELAJARAN PENGENALAN JENIS-JENIS IKAN BERBASIS VIRTUAL REALITY
}

\author{
Gede Thadeo Angga Kusuma ${ }^{1}$, I Made Agus Wirawan², I Ketut Resika Arthana ${ }^{3}$ \\ 1,2,3 Jurusan Pendidikan Teknik Informatika, Universitas Pendidikan Ganesha, \\ Singaraja, Bali
}

e-mail: gedethadeoanggak@gmail.com¹, imade.aguswirawan@undiksha.ac.id², resika@undiksha.ac.id ${ }^{3}$

\begin{abstract}
Abstrak
Tujuan dari penelitian ini adalah untuk mengembangkan sebuah aplikasi Media Pembelajaran Pengenalan Jenis-Jenis Ikan Berbasis Virtual Reality. Adapun tujuan dari pengembangan aplikasi ini adalah untuk membantu proses pembelajaran di TK (Taman Kanak Kanak) dengan tema pengenalan binatang di air khususnya ikan. Ikan yang diperkenalkan pada anak-anak TK (Taman Kanak Kanak) ada 10 jenis ikan air laut. Dengan pengembangan aplikasi ini diharapkan dapat menarik minat belajar anak-anak tentang jenis-jenis ikan yang ada disekeliling kita. Pengembangan aplikasi aplikasi Media Pembelajaran Pengenalan Jenis-Jenis Ikan Berbasis Virtual Reality ini menggunakan model ADDIE. Ada lima tahap dalam model ADDIE yaitu Analisis yang merupakan pengumpulan data melalui wawancara, observasi dan angket kemudian mencari solusi atas permasalahan tersebut, Desain dimana dilakukan perancangan terhadap aplikasi berdasarkan permasalahan, Pengembangan pada tahap ini aplikasi dikembangkan sesuai rancangan, Implementasi yaitu pengujian aplikasi di lapangan untuk melihat respon pengguna terhadap aplikasi yang dikembangkan, dan Evaluasi dimana tahap ini dilakukan untuk mengetahui kelemahan aplikasi sehingga aplikasi dapat diperbaiki. Pengembangan produk dengan model ini dapat menghasilkan produk yang baik, karena pada setiap fase yang dilalui dapat melakukan evaluasi dan revisi. Berdasarkan hasil pengujian yang dilakukan di dapatkan hasil berupa uji whitebox dengan seluruh algoritma yang digunakan berjalan dengan baik dan uji blackbox dengan dua kasus uji mendapat hasil rerata sebesar $100 \%$. Berdasarkan hasil tersebut aplikasi dapat dikatakan berjalan dengan baik sesuai dengan rancangan dan fungsionalnya. Sehingga aplikasi ini dapat dijadikan sebagai media bantuan untuk memperkenalkan jenis-jenis ikan dalam pembelajaran di TK (Taman Kanak Kanak) dengan tema pengenalan binatang di air subtema ikan.
\end{abstract}

Kata kunci: ADDIE, GoogleVR, Ikan Laut, Media Pembelajaran, Virtual Reality

\begin{abstract}
This research aimed at developing a virtual reality based learning media application on the introduction of types of fish. The development of this application intended to facilitate the learning process in the kindergarten concerning on the introduction of aquatic animals, and specifically about fish. There were 10 types of saltwater fish which would be introduced to the kindergarten students. The development of this application is expected to attract children's learning enthusiasm about the types of fish in our environment. The development of this virtual reality based learning media application used ADDIE model. This ADDIE model comprises of 5 stages, Analysis which is collecting data through interview, observation and questionnaire then find solution to the problem, Design where the design of the application based on the problem. Development at this stage the application is developed according to the design, Implementation is testing the application in the field to see the user's response to the application developed, and Evaluation where this stage is done to determine the weakness of the application so that applications can be improved. With the consideration of this model, the developed product could be finalized within fine quality. It could be achieved since this model allows the developer to perform
\end{abstract}


evaluation and revision during every completed stages. Based on the test result performed obtained results in the form of whitebox tests with all algorithms used to run well and blackbox test with two test cases got an average result of 100\%. Based on these results the application run well in according to the design and functional. Therefore, this application could be used as a supporting media to introduce types of fish in the teaching and learning process conducted in the kindergarten, concerning on the theme of aquatic animals with the subtheme of fish.

Keywords : ADDIE, GoogleVR, seawater fish, Introduction of Fish Types, Virtual Reality

\section{PENDAHULUAN}

Secara geografis bumi memiliki luas lautan kurang lebih $70 \%$ atau $2 / 3$ luas dibandingkan dengan luas daratan. Khususnya Indonesia yang dijuluki sebagai negara kepulauan terbesar di dunia dengan lebih dari 17.504 buah pulau, luasnya mencapai 7.7 juta $\mathrm{km} 2$ terdiri dari daratan (2.9 juta $\mathrm{km} 2$ atau $24.7 \%$ ) dan perairan laut (5.8 juta $\mathrm{km} 2$ atau $75.3 \%$ ) [1]. Dengan wilayah lautan yang begitu luas ini tentu juga membentuk keanekaragaman jenis flora dan fauna yang tidak kalah dengan flora dan fauna yang ada di darat, salah satu keanekaragaman founa tersebut adalah Ikan.

Ikan merupakan biota akuatik yang yang hidup di perairan baik sungai, danau, ataupun di lautan. Hewan ini sudah lama menjadi salah satu sumber daya pangan yang dimanfaatkan oleh manusia karena mempunyai nilai ekonomis yang besar. Dengan sifatnya yang mobil, dalam batas tertentu ikan dapat memilih bagian perairan yang layak bagi kehidupannya [2]. Habitat ikan yang ada dibawah air, membuat ikan sulit untuk dilihat secara langsung, karena itu dibutuhkan sebuah teknologi untuk merepresentasikan jenis ikan beserta habitatnya. Virtual Reality menjadi teknologi pilihan yang mampu menangani masalah. Virtual Reality adalah teknologi yang membuat pengguna dapat berinteraksi dengan suatu lingkungan yang disimulasikan oleh komputer, suatu lingkungan sebenarnya yang ditiru atau benar-benar suatu lingkungan yang hanya ada dalam imajinasi. Teknologi Virtual Reality telah banyak diterapkan di beberapa bidang seperti industri, hiburan, militer, pendidikan dan lain sebagainya [3].
Pada tanggal 30 januari 2017 penulis melakukan observasi ke tiga Taman KanakKanak di wilayah singaraja yaitu TK Ceria Asih Singaraja, TK Ganesha, dan TK Sandhy Putra Telkom Singaraja. Berdasarkan hasil observasi tersebut dapat disimpulkan di dapat beberapa kendala dalam proses pembelajaran seperti pembelajaran masih dilakukan secara konvensional dengan media seadanya dan belum adanya pemanfaatan teknologi IT di dalamnya. Khususnya pada pembelajaran dengan tema hewan sub tema hewan di air khususnya jenis ikan, media pembelajaran yang sering digunakan dalam pembelajaran pengenalan jenis ikan antara lain papan tulis, alat peraga, dan gambar-gambar. Dengan teknologi Virtual Reality untuk pengenalan jenis ikan akan sangat bagus untuk menarik minat belajar anak-anak yang pada usia dini rasa ingin tahunya sangat besar, dengn Virtual Reality anak didik dapat merasakan suasana bawah laut dan bentuk-bentuk ikan secara jelas

Ni Gusti Ayu Made Yeni Lestari S.Pd, M.Pd selaku dosen PG PAUD UNDIKSHA juga menyampaikan hal yang serupa yaitu penggunaan teknologi Virtual Reality untuk proses pembelajaran Anak Usia Dini sangat baik dimana anak usia dini belum bisa berpikir abstrak karenanya dibutuhkan benda atau media yang konkrit sehingga pembelajaran menjadi semakin bermakna untuk anak-anak.

Berdasarkan pada permasalahan yang telah dipaparkan di atas, penulis berinisiatif untuk membuat sebuah sebuah Media Pembelajaran "Dunia Ikan" Berbasis Virtual Reality. Dengan adanya media pembelajaran berbasis Virtual Reality ini diharapkan mampu menarik minat anak didik usia dini untuk belajar, khususnya 
proses pembelajaran pada tema hewan bawah laut yaitu ikan. Dalam implementasiannya aplikasi ini dikembangakan untuk perangkat android menggunakan GoogleVR SDK [4] sebagai framework Virtual Reality, Unity 3D [5] untuk membangun aplikasi dari awal sampai selesai, dan Blender [6] untuk membuat objek 3D.

\section{LANDASAN TEORI}

\section{A. Pendidikan Anak Usia Dini}

Taman Kanak-kanak adalah salah satu bentuk satuan pendidikan anak usia dini pada jalur pendidikan formal yang menyelenggarakan program pendidikan bagi anak usia empat tahun sampai enam tahun. Tujuan dari Taman kanak-kanak yaitu untuk membantu anak didik mengembangkan berbagai potensi baik psikis dan fisik yang meliputi moral dan nilai-nilai agama, sosial emosional, kognitif, bahasa, fisik/motorik, kemandirian dan seni untuk siap memasuki pendidikan dasar [7].

Ditinjau dari segi usia, Anak usia dini adalah periode perkembangan yang cepat terjadi dalam banyak aspek perkembangan dan memiliki potensi yang masih harus dikembangkan. Anak usia dini memiliki karakteristik tertentu yang unik dan tidak sama dengan orang dewasa serta akan berkembang menjadi manusia dewasa seutuhnya. Dalam hal ini anak merupakan seorang manusia atau individu yang memiliki pola perkembangan dan kebutuhan tertentu yang berbeda dengan orang dewasa [8]. Proses pembelajaran untuk anak usia dini harus memperhatikan karakteristik yang dimiliki anak pada setiap perkembangan anak. Oleh sebab itu untuk menunjang kegiatan bermain dan belajar perlu di dukung oleh media yang menarik dengan karakteristik perkembangan anak. Dalam penelitian ini studi kasus yang akan dilakukan adalah di Taman Kanak-Kanak yaitu TK Ceria Asih Singaraja.

\section{B. Ikan}

Ikan merupakan biota akuatik yang bersifat mobil atau nekton yang hidup diperairan baik sungai, danau, ataupun di lautan. Hewan ini sudah lama menjadi salah satu sumber daya pangan yang dimanfaatkan oleh manusia karena mempunyai nilai ekonomis yang besar. Dengan sifatnya yang mobil, dalam batas tertentu ikan dapat memilih bagian perairan yang layak bagi kehidupannya [2]. Berdasarkan hasil angket respon anak-anak terhadap jenis-jenis ikan yang dikenal di taman kanak-kanak akan dipilih 10 jenis ikan dengan persentase tertinggi yang nantinya akan di perkenalkan dalam media pembelajaran pengenalan jenis ikan. berdasarkan wawancara dan kesesuaian materi untuk anak-anak usia dini akan diperkenalkan 10 jenis ikan air laut yaitu Ikan Tongkol, Ikan Hiu, Ikan Pari, Kuda Laut, Ikan Kakap, Ikan Badut, Ikan Layaran, Ikan Cakalang, Ikan Tuna, dan Ikan Buntal.

\section{Android}

Android is a software stack for mobile devices that includes an operating system, middleware and key applications. Most of you may already be aware of Android, its capabilities and other aspects. [9] Android 4.0 atau Ice Cream Sandwich akan digunakan sebagai standar minimal agar aplikasi dapat dijalankan.

\section{Virtual Reality}

Virtual Reality adalah teknologi yang membuat penggunadapat berinteraksi dengan suatu lingkungan yang disimulasikan oleh komputer (komputersimulated environment) [10]. Lingkungan Virtual Reality terkini umumnya menyajikan pengalaman visual yang ditampilkan pada sebuah layar komputer, tetapi beberapa simulasi virtual reality tingkat tinggi mengikutsertakan juga tambahan informasi hasil pengindraan mata melalui kacamata, suara melalui speaker dan headseat, gerakan tangan melalui glove dan gerakan kaki menggunakan peralatan walker [11].

\section{E. GoogleVR SDK}

Google VR SDK for Unity adalah framework yang disediakan oleh google untuk membantu para pengembang untuk membuat sebuah aplikasi berbasis Virtual Reality (VR) yang secara langsung 
terintegrasi dengan Unity. Unity native integration dengan Google VR memudahkan untuk membangun aplikasi android untuk Daydream dan Cardboard [4].

\section{F. Unity 3D}

Unity 3D adalah sebuah game engine yang berbasis cross-platform. Unity dapat digunakan untuk membuat sebuah game yang bisa digunakan pada perangkat komputer, ponsel pintar android, iPhone, $P S 3$, dan bahkan $X-B O X$. Unity adalah sebuah sebuah tool yang terintegrasi untuk membuat game, arsitektur bangunan dan simulasi [5].

\section{G. Blender}

Blender adalah perangkat penciptaan 3D yang gratis dandan open source. Aplikasi ini mendukung keseluruhan pemodelan pipa 3D, rigging, animasi, simulasi, rendering, compositing dan motion tracking, bahkan editing video dan pembuatan game [6].

\section{METODOLOGI}

\section{A. Jenis Penelitian}

Pengembangan Media Pembelajaran "Dunia Ikan" Berbasis Virtual Reality untuk anak-anak di TK Ceria Asih Singaraja ini termasuk penelitian pengembangan Research and Development (R\&D). Penelitian Pengembangan Research and Development (R\&D) adalah sebuah proses yang digunakan untuk mengembangkan produk atau sistem.

\section{B. Model Pengembangan}

Model yang digunakan dalam penelitian ini adalah ADDIE. ADDIE adalah akronim dari Analysis, Design, Development, Implementation, dan Evaluation. Prosedur pengembangan dalam model $A D D I E$ terdiri dari lima tahap. Kelima tahap tersebut adalah Analyze (Analisis), Design (Desain), Development (pengembangan), Implementation (Implementasi), dan Evaluation (evaluasi) [12]

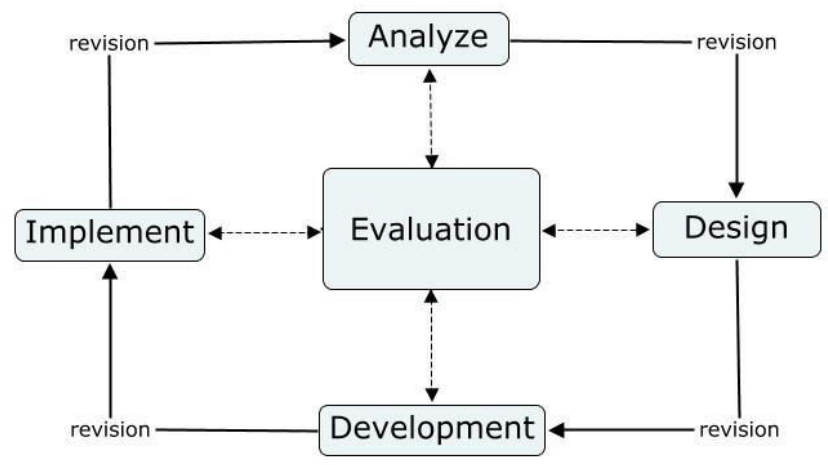

Gambar 1. ADDIE Model (sumber: http://educationaltechnology.net/the-addie-modelinstructional-design)

\section{A. Analisis}

Tahap pertama yang dilakukan adalah mencari dan mengumpulkan kebutuhan secara lengkap kemudian dianalisis dan didefinisikan yang merupakan bagian dari analysis (analisis) pada model tersebut.

\section{Analisis Masalah}

a. Berdasarkan hasil wawancara dengan tiga narasumber yang merupakan kepala sekolah TK di singaraja dapat di simpulkan bahwa proses pembelajaran masih dilakukan secara konvensional dengan media-media seadanya dan belum adanya pemanfaatan teknologi IT di dalamnya.

b. Penggunaan media pembelajaran yang sama terus menerus tak jarang membuat anak didik jadi merasa bosan saat belajar.

c. Perkembangan IT yang begitu pesat tiap tahunnya, dirasakan perlu mengembangkan media 
pembelajaran berbasis IT sehingga pilihan dalam penggunaan media pembelajaran jadi lebih variatif dan inovatif dan anak didik akan lebih bersemangat dalam belajar mengenai berbagai hal baru.

2. Kebutuhan Fungsional

a. Pengguna mampu menampilkan objek 3D jenis-jenis ikan air tawar dan ikan air laut yang bergerak dengan suasana bawah air yang nyata.

b. Pengguna dapat menampilkan ensiklopedia ikan dan informasi mengenai ikan-ikan yang ditampilkan pada aplikasi.

c. Pengguna mampu menampilkan informasi tentang aplikasi dan identitas pengembang dengan menekan tombol tentang.

d. Pengguna dapat mengatur suara.

3. Kebutuhan Non Fungsional a. Berjalan pada perangkat dengan sistem operasi Android minimal versi 4.1 (Jelly Bean) dan memiliki sensor gyroscope.

b. Memiliki tampilan yang user friendly, tujuannya agar pengguna tidak kesulitan dalam menggunakan aplikasi dan tertarik untuk menggunakan aplikasi. User friendly yang dimaksud yaitu perpaduan warna yang menarik antara background dan softbutton, serta kemudahaan dalam penggunaan aplikasi dengan tampilan antar muka yang simple dan mudah dipahami baik oleh anak-anak maupun orang dewasa.

c. Aplikasi dapat mengikuti gerakan device.

4. Use Case

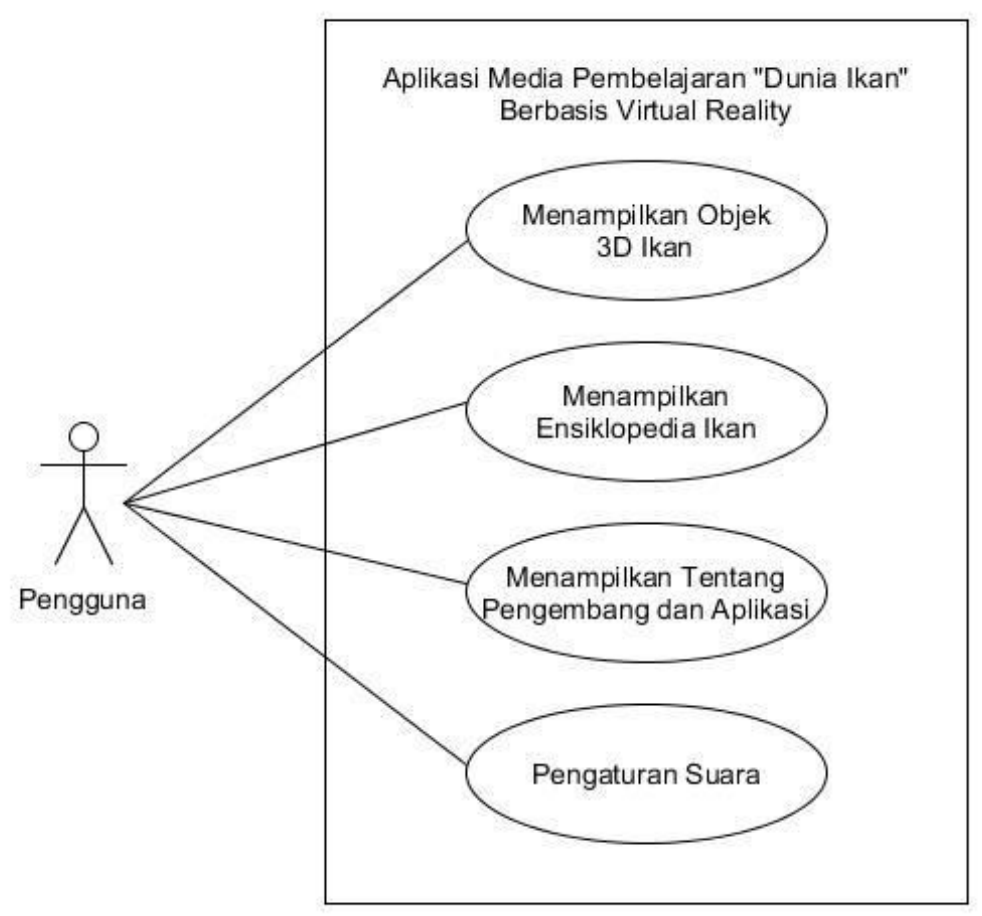

Gambar 2. Use Case Aplikasi Media Pembelajaran "Dunia Ikan” Berbasis Virtual Reality

B. Desain

1. Batasan Perancangan

Adapun batasan perancangan

aplikasi Media Pembelajaran "Dunia Ikan"
Berbasis Virtual Reality dapat dipaparkan sebagai berikut

a. Aplikasi menampilkan 10 objek 3D ikan air tawar yaitu Ikan Koi, Ikan 
Lele, Ikan Mas, Ikan Mujair, Ikan Arwana, Ikan Cupang, Ikan Nila, Ikan Patin, Ikan Gurame, dan Ikan Louhan

b. Aplikasi menampilkan 10 objek 3D ikan air laut yaitu Ikan Tongkol, Ikan Hiu, Ikan Pari, Kuda Laut, Ikan Teri, Ikan Badut, Ikan Layaran, Ikan Cakalang, Ikan Tuna, dan Ikan Buntal.Aplikasi hanya dapat dijalankan pada smartphone yang memiliki Sensor Gyroscope dan Sensor Accelorometer:

c. Aplikasi ini dapat berjalan optimal pada perangkat keras

smartphone dengan kecepatan processor minimal 1Ghz, RAM minimal $1 \mathrm{~GB}$, dan resolusi layar $1024 \times 768$

d. Aplikasi akan bekerja lebih baik jika menggunakan Bluetooth Mini Gamepad atau gamepad sejenis yang menggunakan koneksi Bluetooth, sehingga dapat tersambung dengan smartphone.

2. Rancangan Antarmuka Perangkat Lunak

a. Rancangan Antarmuka Tampilan Layar Splash screen

Tampilan Splash screen atau tampilan awal sebelum masuk ke Menu Utama.

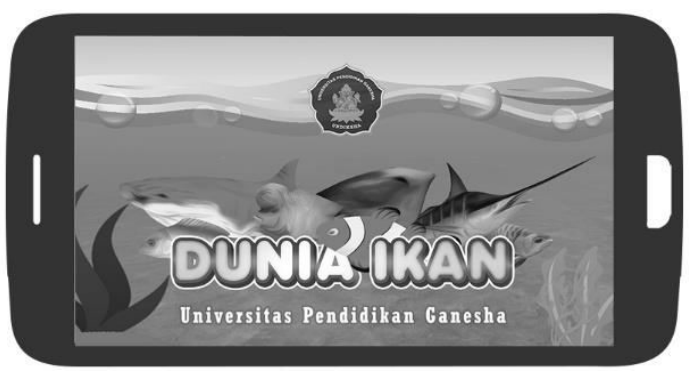

Gambar 4. Rancangan Antarmuka Tampilan Layar Splash Screen

b. Rancangan Antarmuka Tampilan Menu Utama

Aplikasi yang dikembangkan memiliki 4 menu utama, yaitu Mulai untuk memulai aplikasi dan menampilkan pilihan menu jenis ikan yang ingin dikenal yaitu ikan air tawar atau ikan air laut. Ensiklopedia untuk menampilkan informasi semua ikan yang

$\begin{array}{lccr}\text { ditampilkan } & \text { dalam } & \text { aplikasi } & \text { media } \\ \text { pembelajaran } & \text { ini. } & \text { Tentang } & \begin{array}{r}\text { untuk } \\ \text { menampilkan }\end{array} \\ \text { tentang } & \text { identitas }\end{array}$

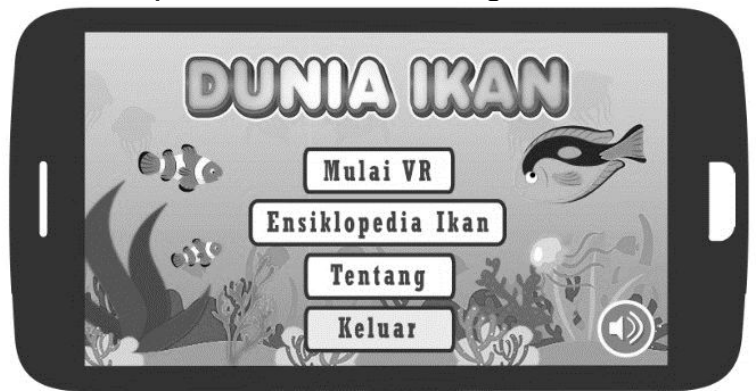

pengembang dan aplikasi, dan keluar untuk menutup aplikasi.

\section{Gambar 5. Rancangan Antarmuka Tampilan Menu}

\section{c. Rancangan Antarmuka Tampilan Ensiklopedia Ikan}

Pada scene ini akan menampilkan daftar jenis ikam yang ditampilkan pada aplikasi media pembelajaran ini. Jika ingin melihat informasi ikan selanjutnya dapat menekan softbutton kanan dan jika ingin melihat informasi ikan sebelumnya dapat menekan softbutton kiri.

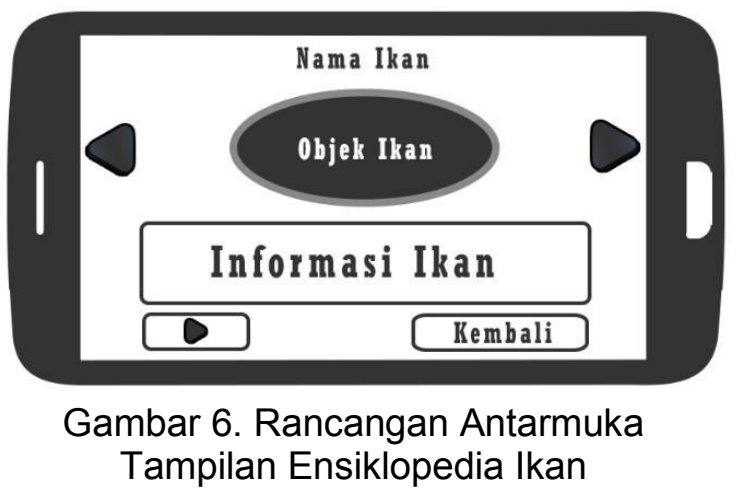

d. Rancangan Antarmuka Tampilan Tentang Scene ini menampilkan informasi tentang pengembang dan aplikasi.

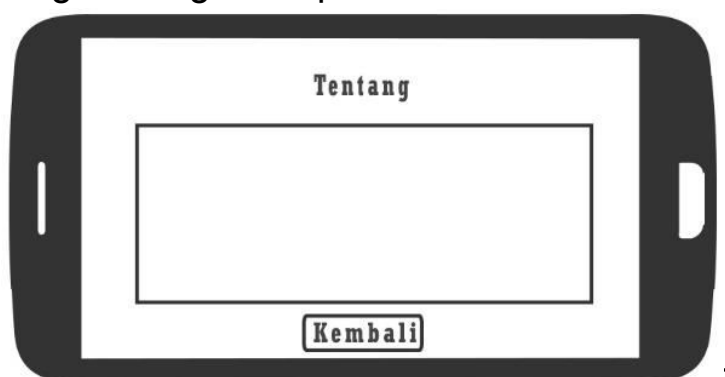


Gambar 7. Rancangan Antarmuka

Tampilan Tentang

\section{Pengembangan}

Pengembangan dalam model ADDIE berisi kegiatan realisasi rancangan produk. Dalam tahap desain, telah disusun kerangka aplikasi. Dalam tahap pengembangan, kerangka yang masih konseptual tersebut direalisasikan menjadi produk yang siap diimplementasikan, Berikut perangkat lunak dan perangkat keras yang digunakan dalam pengembangan aplikasi Media Pembelajaran "Dunia Ikan" Berbasis Virtual Reality.

1. Kebutuhan Perangkat Lunak

Adapun perangkat lunak yang digunakan dalam membangun aplikasi ini adalah sebagai berikut:

a. Musik dan Sound, aplikasi yang digunakan untuk mengembangkan ialah Audacity, untuk memotong beberapa music.

b. Grafis, aplikasi yang digunakan untuk mengembangkan ialah GIMP untuk membuat texture dan mendesain menu aplikasi serta Blender untuk membuat objek 3D dan animasi yang berupa objek 3D ikan, environment atau lingkungan bawah laut, rumput laut dan kebutuhan assets 3D lainnya.

c. Virtual Reality, aplikasi yang digunakan untuk mengembangkan ialah Unity $3 D$ sebagai sebagai game engine untuk pengembangan aplikasi Virtual Reality, Google VR SDK for Unity sebagai library utama pengembangan aplikasi Virtual
Reality serta C Sharp atau C\# sebagai bahasa pemrograman pengembangan aplikasi Virtual Reality.

2. Kebutuhan Perangkat Keras

Dalam pembuatan aplikasi yang dimulai dari perancangan, pengkodean, hingga implementasi dibutuhkan perangkat keras laptop dan mobile device yang dalam hal ini adalah smarthphone bersistem operasi Android. Daftar perangkat keras yang digunakan untuk pembuatan dan pengujian awal aplikasi adalah sebagai berikut :

a. Laptop Model : HP Pavilion G4, Processor : Intel Core i7-3632QM 2.2 $\mathrm{GHz}$, Harddisk : 750GB, Memory : 8GB, VGA : AMD Radeon $2 \mathrm{~GB}$

b. Smartphone Model: Asus Zenfon 2 , Sistem Operasi : Android OS v 4.4.2 (Kitkat), Memory (RAM) : 2 GB, Sensor Gyroscope. : : Ada, Sensor Accelorometer. Ada, Bluetooth Mini Gamepad

C. VR Box 2

\section{Implementasi}

Pada tahap ini peneliti akan melakukan implementasi Media Pembelajaran "Dunia Ikan" Berbasis Virtual Reality di TK Ceria Asih Singaraja. Aplikasi akan diterapkan saat pembelajaran dengan sub tema binatang di air. Adapun tahapan dalam melakukan implementasi aplikasi Virtual Reality Pengenalan Jenis-Jenis Ikan dapat dilihat pada Tabel 1 berikut.

\begin{tabular}{|c|c|}
\hline Tahap & Penjelasan \\
\hline 1 & $\begin{array}{l}\text { Peneliti memperkenalkan aplikasi Media Pembelajaran “Dunia Ikan” Berbasis } \\
\text { Virtual Reality kepada guru pengajar di TK Ceria Asih Singaraja. }\end{array}$ \\
\hline & Peneliti menjelaskan tata cara menggunakan aplikasi Media Pembelajaran "Dunia \\
\hline 2 & $\begin{array}{l}\text { Ikan" Berbasis Virtual Reality mulai dari membuka aplikasi, memilih menu, dan } \\
\text { cara melihat objek ikan beserta informasinya. }\end{array}$ \\
\hline 3 & $\begin{array}{l}\text { Guru mengenalkan jenis-jenis ikan menggunakan aplikasi Media Pembelajaran } \\
\text { "Dunia Ikan" Berbasis Virtual Reality kepada anak-anak. }\end{array}$ \\
\hline 4 & $\begin{array}{l}\text { Guru mendampingi ketika anak-anak menggunakan aplikasi Media Pembelajaran } \\
\text { "Dunia Ikan" Berbasis Virtual Reality. }\end{array}$ \\
\hline $\begin{array}{l}\text { Ev } \\
\text { Ta } \\
\text { im }\end{array}$ & $\begin{array}{l}\text { dilakukan dengan tujuan mengetahui } \\
\text { kekurangan dan kelemahan maupun } \\
\text { kesalahan (error) dari aplikasi yang }\end{array}$ \\
\hline
\end{tabular}


dikembangkan, sehingga aplikasi masih bisa diperbaiki untuk mengurangi kesalahan-kesalahan yang terjadi sebelum aplikasi di rilis ke masyarakat luas. Pada tahap evaluasi akan dilakukan 2 jenis pengujian yaitu Uji Whitebox dan Uji Blackbox dengan dua kasus uji yaitu kebenaran proses pada aplikasi dan penggunaan aplikasi pada 5 perangkat yang berbeda. Pada perhitungan hasil pengujian blackbox pengguna menggunakan angket dengan beberapa butir pernyataan.

\section{HASIL DAN PEMBAHASAN}

Hasil penelitian yang telah dilakukan adalah sebuah aplikasi edukasi Virtual Reality "Dunia Ikan" yang dapat dijalankan pada perangkat smartphone android yang yang sudah mendukung sensor gyroscope. Adapun hasil pengembangan apliaksi virtual reality pengenalan jenis-jenis ikan dapat dilihat pada gambar berikut.

\section{A. Implementasi Antarmuka Aplikasi}

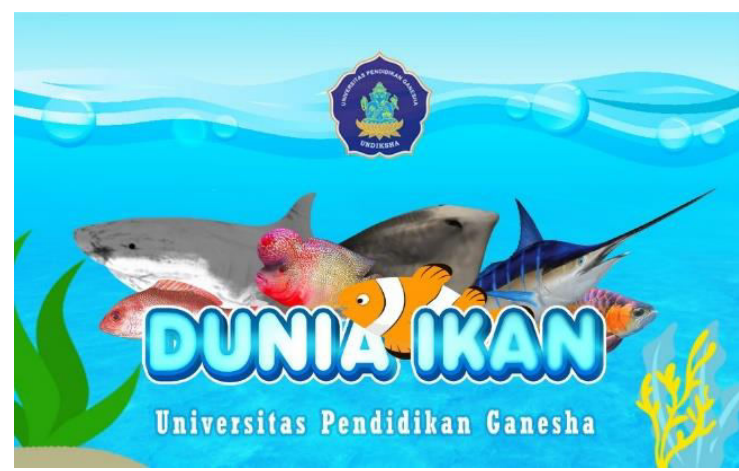

Gambar 8. Tampilan Awal (Splashscreen)

Pada gambar 8 merupakan tampilan Splash Screen atau Tampilan awal yang muncul beberapa detik sebelum masuk ke menu utama. Pada implementasi Splash Screen dibuat dengan tema laut dengan ditampilkan judul aplikasi dan gambar ikan serta logo Undiksha.

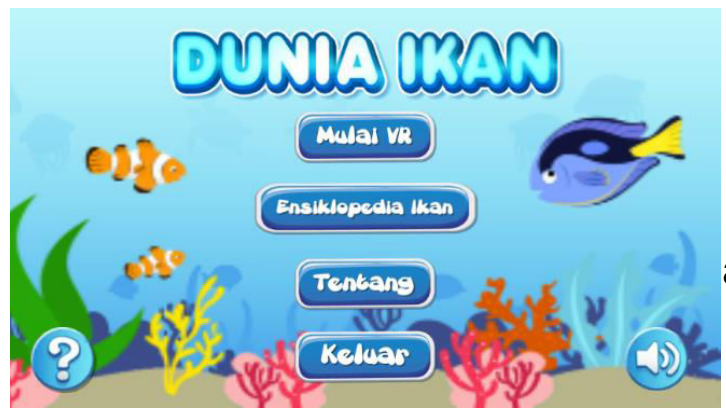

\section{Gambar 9. Hasil Antarmuka Menu Utama}

Gambar 9 merupakan tampilan Main Menu atau menu utama. Pada menu utama ada empat button pilihan yang dapat digunakan yaitu button Mulai VR untuk memulai penjelajahan dasar laut dan pengenalan jenis ikan, button Ensiklopedia Ikan untuk menampilkan informasi jenisjenis ikan yang ada pada aplikasi ini, button tentang untuk menampilkan informasi terkait pengembang, button suara yang berfungsi untuk menampilkan menu pengaturan suara sehingga kita dapat mengatur suara musik dan narasi pada aplikasi, dan yang terakhir adalah button Keluar yang berfungsi untuk keluar dari aplikasi.

\section{Gambar 10. Tampilan Antarmuka Ensiklopedia Ikan}

\section{Gambar 10 merupakan tampilan}

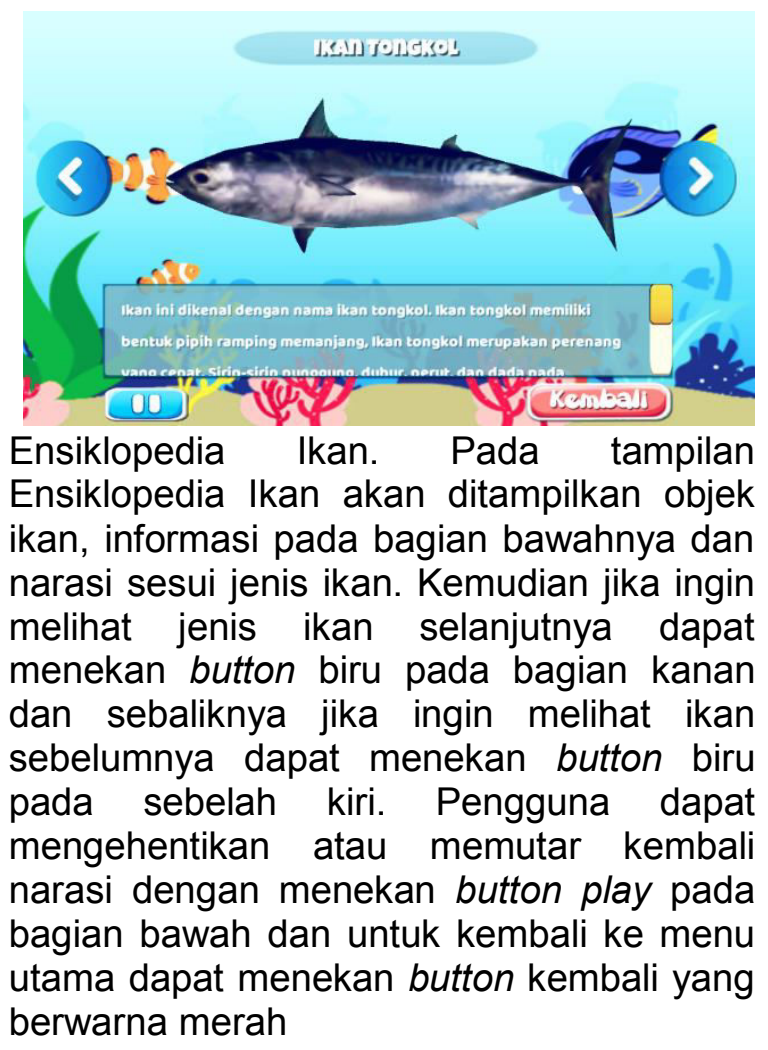




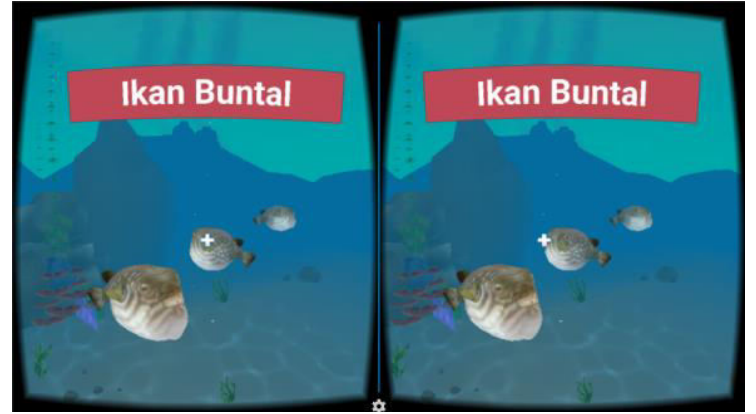

Gambar 11. Hasil Antarmuka Main Play

Gambar 11 merupakan tampilan Main Play. Scene ini merupakan tampilan Virtual Reality saat kita memilih button Mulai VR dan memilih kategori jenis ikan yang ada dua yaitu ikan air tawar dan ikan air laut. Pada Tampilan Main Play pengguna akan diajak menjelajah di dalam air untuk mengenal berbagai jenis ikan, kemudia saat pengguna menunjuk pada objek ikan akan ditampilkan nama ikan tersebut. Pengguna dapat melihat detail informasi dari ikan yang ditunjuk dengan menekan button $\mathrm{A}$ atau mengclick pada objek ikan tersebut dan akan di alihkan pada tampilan Deksripsi

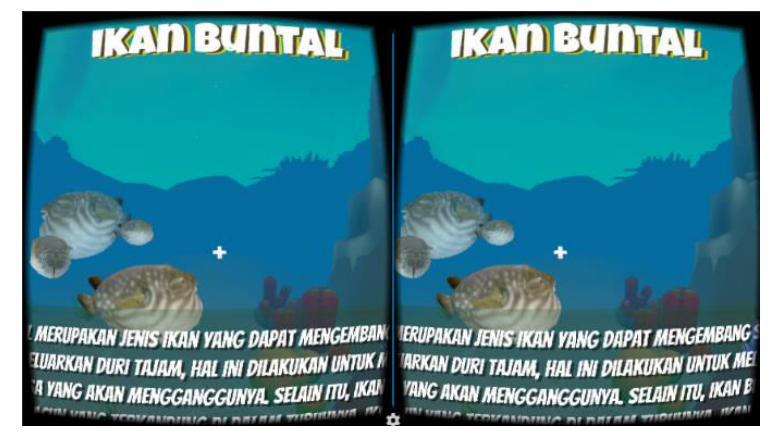

Gambar 12. Hasil Antarmuka Deskripsi

Gambar 12 merupakan Tampilan Deskripsi yang merupakan tampilan saat kita memilih salah satu jenis ikan pada Main Play. Pada tampilan Deskripsi akan ditampilkan objek 3D Ikan, informasi singkat ikan dan narasi dalam mode Virtual Reality, kita dapat kembali ke Main Play dengan menekan button Kembali.

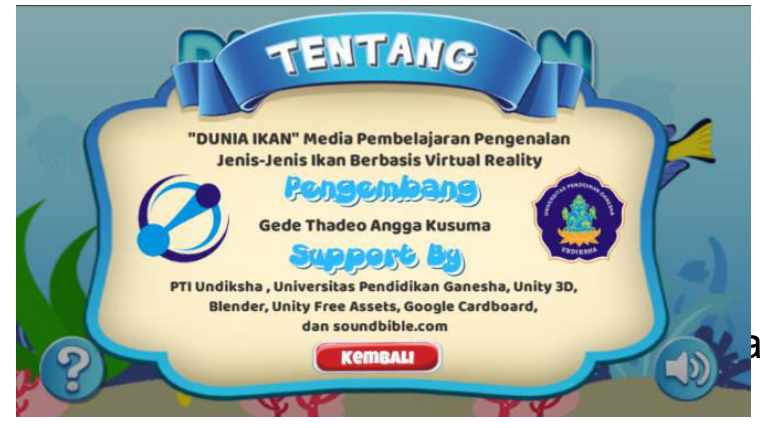

\section{Gambar 13. Hasil Antarmuka Tentang}

Gambar 13 merupakan tampilan Tentang yang berisi informasi tentang pengembang dan aplikasi pendukung yang digunakan dalam pengembangan aplikasi.

\section{B. Implementasi Pengujian}

\section{Uji Whitebox}

Pelaksanaan pengujian white box perangkat lunak berupa pengujian algoritma dan analisis kode dari program yang dibuat untuk memastikan tidak ada bug atau kesalahan di dalam program. Pengujian whitebox dilakukan pada hari senin, 28 Agustus 2017. Dari hasil pengujian white box untuk uji algoritma tersebut dapat dinyatakan bahwa semua algoritma yang digunakan dalam pengembangan perangkat lunak Media Pembelajaran Pengenalan Jenis-Jenis Ikan Berbasis Virtual Reality sudah benar dan output sudah sesuai dengan fungsi dan tujuan dari tiap algoritma yang digunakan.

\section{Uji Blackbox}

Pelaksanaan pengujian black box tediri atas dua kasus uji yaitu pengujian kebenaran proses dan penggunaan aplikasi pada 5 perangkat yang berbeda. Uji Kebenaran Proses

a. Pelaksanaan Pengujian Kebenaran Proses

Pengujian kebenaran proses memiliki tujuan untuk menguji kebenaran proses perangkat lunak Media Pembelajaran Pengenalan Jenis-Jenis Ikan Berbasis Virtual Reality yang telah dikembangkan sehingga seluruh proses yang telah direncanakan di awal dapat berjalan sebagaimana mestinya. Pada tahap lima orang mahasiswa diminta untuk menggunakan aplikasi Media Pembelajaran Pengenalan Jenis-Jenis Ikan Berbasis Virtual Reality dan setelah menggunakan 
aplikasi masing-masing mahasiswa diberikan angket kebenaran proses. Pengujian kebenaran proses ini dilaksanakan pada 16 Agustus 2017. Dari hasil pengujian semua proses dimulai dari pertama kali aplikasi dijalankan sampai dengan keluar dari aplikasi, proses sudah berfungsi dengan baik dengan persentase 100\%. Uji Kelayakan Sebagai Game Edukasi Pengenalan Buah Lokal Bali

b. Pelaksanaan Pengujian Penggunaan Aplikasi Pada Lima Perangkat Berbeda

Pengujian Penggunaan Aplikasi Pada Lima Perangkat Berbeda dilakukan untuk mengetahui jalannya aplikasi pada lima perangkat yang bereda sudah benar atau belum. Pada tahap lima orang mahasiswa diminta untuk menggunakan aplikasi Media Pembelajaran Pengenalan Jenis-Jenis Ikan Berbasis Virtual Reality dan setelah menggunakan aplikasi masing-masing mahasiswa diberikan angket pengujian aplikasi pada perangkat yang berbeda. Pengujian penggunaan aplikasi pada lima perangkat yang berbeda dilaksanakan pada 11 Agustus 2017.

Pada pelaksanaan pengujian 5 jenis smartphone yang digunakans yaitu smartphone Asus Zenfone 2, Xiaomi Redmi Note 2, Xiaomi Redmi 4 Prime, Oppo A37, dan Sony Xperia 2. Dari hasil pengujian semua proses dimulai dari pertama kali aplikasi dijalankan sampai dengan keluar dari aplikasi, proses sudah berfungsi dengan baik dengan persentase $100 \%$.

\section{SIMPULAN}

Berdasarkan hasil analisis, implementasi dan pengujian pada penelitian pengembangan aplikasi Media Pembelajaran Pengenalan Jenis-Jenis Ikan Berbasis Virtual Reality dapat ditarik kesimpulan sebagai berikut.

1. Perancangan Aplikasi Media Pembelajaran Pengenalan JenisJenis Ikan Berbasis Virtual Reality menggunakan metode permodelan UML atau Unified Modelling
Language yang berupa use case dan activity diagram. Pada tahan Implementasi mengguna beberapa aplikasi yaitu bahasa pemrograman $\mathrm{C}$ sharp, Unity untuk pembuatan aplikasi berbasis Virtual Reality dengan framework GoogleVR SDK for Unity, Blender 3D untuk pembuatan objek 3D ikan dan environment bawah air beserta animasi pergerakan ikan, GIMP untuk membuat tekstur, icon dan gambar latar, dan audacity untuk mengedit suara narasi. Aplikasi Media Pembelajara "Dunia Ikan" berbasis Berbasis Virtual Reality dapat dipasang pada smartphone Android dengan sistem Ice Cream Sandwich ke atas. Aplikasi Media Pembelajara "Dunia Ikan" berbasis Berbasis Virtual Reality mampu menampilan jenisjenis ikan, serta pengguna dapat mengenal ikan baik itu ikan air tawar dan ikan air laut dan merasakan suasana bawah air sesuai jenis ikan.

2. Evaluasi Aplikasi Media Pembelajara "Dunia Ikan" berbasis Berbasis Virtual Reality di TK Ceria Asih kelas B mendapatkan hasil yang baik dari uji whitebox dengan hasil seluruh kode berjalan sesuai fungsinya dan uji blackbox juga mendapatkan hasil yang serupa, pada kasus uji 1 dan 2 dari 5 responden hasil rerata sebesar $100 \%$ artinya aplikasi dapat berjalan dengan baik pada perangkat smarthphone.

\section{SARAN}

Berdasarkan pengamatan peneliti dilapangan, terdapat beberapa hal yang dapat dijadikan bahan pertimbangan untuk pengembangan berikutnya.

Diantaranya adalah sebagai berikut

1. Aplikasi Media Pembelajara "Dunia Ikan" berbasis Berbasis Virtual Reality memiliki texture yang tidak terlalu detail oleh karena itu untuk pengembangan aplikasi Virtual Reality pada Android selanjutnya, agar memperhatikan teknik texturing sehingga dapat menghasilkan objek 
dengan texture yang jelas namun tidak mengurangi kecepatan aplikasi.

2. Aplikasi ini masih memiliki keterbatasan pada objek ikan dan objek tumbuhan bawah laut, sehingga untuk pengembangan selanjutnya objek ikan dapat diperbanyak untuk memberikan pengetahuan yang lebih banyak dan suasana bawah air yang lebih kental.

3. Aplikasi ini masih melakukan Loading yang lumayan lama, untuk kedepannya dapat lebih meminimalkan waktu Loading.

4. Pada tahap pengembanganpengembangan selanjutnya perlu diadakan analisis UX (user experience) dengan metode yang berbeda agar pengembang memahami kebutuhan baik desain maupun fitur yang bisa dikembangkan.

\section{DAFTAR PUSTAKA}

[1] Kementrian Kelautan dan Perikanan Republik Indonesia, "MEMBANGUN KELAUTAN UNTUK

MENGEMBALIKAN KEJAYAAN SEBAGAI NEGARA MARITIM," 2014. [Online]. Available: http://www.ppkkp3k.kkp.go.id/ver2/news/read/115/me mbangun-kelautan-untuk-

mengembalikan-kejayaan-sebagainegara-maritim.html. [Accessed 6 Februari 2017].

[2] M. Fachrul, Metode Sampling Bioekologi, Jakarta: Penerbit Bumi Aksara, 2007.

[3] B. D. Sihite, "Pembuatan Aplikasi 3D Viewer Mobile dengan Menggunakan Teknologi Virtual Reality," JURNAL TEKNIK POMITS, Vols. Vol. 2, No. 2, pp. 397-398, 2013.

[4] Google, "Google VR SDK for Unity," 9 Februari 2017. [Online]. Available: https://developers.google.com/vr/unity/

[5] Unity Technologies, "Getting Started," 2015. [Online]. Available: http://docs.unity3d.com/Manual.
[Accessed 17 Februari 2017].

[6] Blender Foundation, "About Blender," 2015. [Online]. Available: https://www.blender.org/about/. [Accessed 17 Februari 2017].

[7] Depdiknas, "Standar Kompetensi Taman Kanak-kanak \& Raudhatul Athfa," Pusat Kurikulum, Badan Penelitian dan Pengembangan, Jakarta, 2003.

[8] Wahyudin, Uyu and M. Agustin, Penilaian Perkembangan Anak Usia Dini: Panduan untuk Guru, Tutor, Fasilitator, dan Pengelola Pendidikan Anak Usia Dini, Bandung: PT Refika Aditama, 2012.

[9] A. Developer, "What is android," 2011.

[10] Anna, "Implementasi Obyek 3D Virtual Reality".

[11] Suwarto, "Desain Dan Implementasi Virtual Reality 3D Perpustakaan Universitas Brawijaya," 2014.

[12] G. Muruganantham, "Developing of Econtent package by using ADDIE Model," International Journal of Applied Research, pp. 52-54, 2015.

[13] M. D. T. D. J. a. P. J. S. MAAIKE J. VAN DEN HAAK, "Retrospective vs. concurrent think-aloud," BEHAVIOUR \& INFORMATION TECHNOLOGY, vol. 22, no. 5, p. 339-351, 2003.

[14] I. M. Tegeh and I. M. Kirna, Metode Penelitian Pengembangan Pendidikan, Singaraja: Universitas Pendidikan Ganesha, 2010. 